Research paper

\title{
Evolution of hydraulic properties and wettability of organic growing media during cultivation according to irrigation strategies
}

\author{
Jean-Charles Michel*, Eric Kerloch \\ UPSP EPHor Physical Environment of the Horticultural Plant, AGROCAMPUS OUEST, 2 rue Le Nôtre, 49045 Angers, Cedex 01, France
}

\section{A R T I C L E I N F O}

\section{Article history:}

Received 15 April 2016

Received in revised form

10 November 2016

Accepted 13 January 2017

Available online 22 January 2017

\section{Keywords:}

Wettability

Relative gas diffusivity

Pore tortuosity

Water retention

Air filled porosity

\begin{abstract}
A B S T R A C T
Recent studies have shown that growth period largely affected physical properties of growing media, and therefore irrigation management has to be revised according to these changes in order to avoid poor irrigation. Decreases in pore tortuosity but also in wettability have been identified as the most relevant parameters explaining these evolutions with time, as a result of combined effects of root growth and irrigation regimes. So, this study aimed to analyse the respective effects of root development and irrigation strategies on the physical and hydraulic properties of four different growing media (peat, pine bark, coir and wood fiber) within a culture of Rosa $\times$ hybrida "Radrazz" grown with and without plants during four months, for which watering was managed in three different ways: (1) water potential always maintained at $-1 \mathrm{kPa},(2)$ irrigation triggered when water potential reached $-10 \mathrm{kPa}$ or (3) $-30 \mathrm{kPa}$.

Root volume, total volume, air and water retention properties, hydraulic conductivity, relative gas diffusivity, and wettability were evaluated at the beginning and at the end of the experiment. The study showed important changes over time, mainly due to the hydric history, leading to large and higher modifications of pore size distribution, tortuosity and wettability as a function of the intensity of the drying/wetting cycles. Changes in wettability, and notably, more hydrophobic properties of the coarser porosity due to its drainage during the drying processes were suggested for explaining the general physical/hydraulic behaviour of growing media, and the decrease in shoot dry mass and root content with the intensity of irrigation regimes. Although they were with smaller amplitude to those resulting of the hydric history, positive effects of the root system were shown, increasing pore connectivity, relative gas diffusivity and limiting the decrease in total pore volume, and moreover, limiting the degradation in wettability.
\end{abstract}

(C) 2017 Elsevier B.V. All rights reserved.

\section{Introduction}

Precise irrigation management of substrates is of vital importance in horticultural soilless systems to avoid root asphyxia, nutrient leaching, and plant disease in case of excessive watering; as well as, nutrient and water deficiency, and then plant physiological stress in the driest conditions. Therefore, studying the evolution of physical and hydraulic properties of substrates during plant cultivation is absolutely necessary due to the changes that root development and the multiple alternations of drying (evapotranspiration) and watering (irrigation) periods which can occur. This can likely lead to changes in these physical properties, and then in water, air and nutrient availability for plant, with a risk to lead to a poor fertigation management, and then decreases in plant

\footnotetext{
* Corresponding author.

E-mail address: jean-charles.michel@agrocampus-ouest.fr (J.-C. Michel).
}

yield and/or quality, or more irremediable crop failures. Kerloch and Michel (2015), in their last paper, reported and confirmed previous works showing these changes in physical properties during time, with contradictory effects observed according to particle size distributions of the growing media. All authors mentioned decreases in air-filled porosity and pore tortuosity because of root growth in the macroporosity progressively filled by them (AllaireLeung et al., 1999; Nkongolo and Caron, 2006; Caron et al., 2010; Cannavo and Michel, 2013; Kerloch and Michel, 2015). However, Caron et al. (2010) and Cannavo and Michel (2013) showed the decrease in the resulting relative gas diffusivity for fine growing media, whereas Allaire-Leung et al. (1999), Cannavo and Michel (2013), and Kerloch and Michel (2015) reported its increase for coarser materials used in their trials (peat, pine bark, coco, and wood fiber). Also, Allaire-Leung et al. (1999) and Kerloch and Michel (2015) reported increases in water retention at $-1 \mathrm{kPa}$ for fine peat based growing media, whereas coarser materials like pine bark, wood fiber and coir did not show any significant change (Kerloch 
and Michel, 2015). Opposite evolutions were also observed for hydraulic conductivity, sometimes with a decrease, respectively for peat, wood and coir growing media (Cannavo et al., 2011; Gruda and Schnitzler 2004; Kerloch and Michel, 2015), sometimes without change for peat-based mixes (Allaire-Leung et al., 1999; Nkongolo and Caron, 2006), and sometimes with an increase for peat, pine bark and wood fiber (Kerloch and Michel, 2015), but all these changes in hydraulic conductivity are always low, not exceeding one order of magnitude in all cases.

Besides particle size distribution, most works do not provide information about irrigation regimes. Indeed, the effects and the amplitude of drying/wetting cycles were already emphasized, affecting air and water retention and flow (da Silva et al., 1993; Naasz et al., 2005; Wallach et al., 1992; Qi et al., 2011), the total pore volume (Fonteno et al., 1981; Gruda and Schnitzler, 2004; Heiskanen, 1995; Qi et al., 2011) and the growing medium's wettability (Michel et al., 2001; Naasz et al., 2008; Fields et al., 2014; Michel, 2015). In their experiment, Kerloch and Michel (2015) reported degradations in physical properties of peat, pine bark, coir and wood fiber, and mainly explained that by their decrease in wettability.

The aim of this work was then to investigate the evolutions of the physical and hydraulic properties of four growing media (peat, pine bark, coir and wood fiber) during a 4-month growth period of Radrazz Rosa $\times$ hybrida according to three different irrigation strategies: (1) water potential always maintained at $-1 \mathrm{kPa},(2)$ irrigation triggered when water potential reached $-10 \mathrm{kPa}$ or (3) $-30 \mathrm{kPa}$. The evolutions in terms of root development, and of air and water storage and flow properties as a function of intensity of drying, aimed to verify the hypothesis reported by Qi et al. (2011) and Kerloch and Michel (2015) of degradation in wettability as one of the most relevant parameters explaining evolutions of physical properties. Also, comparing results obtained on growing media with or without plants for which irrigation was managed in the same way tried to estimate the respective weights of root development and hydric history (drying/wetting cycles) on the evolution of physical properties over time.

\section{Materials and methods}

\subsection{Experimental procedure}

The experiment was conducted in a glasshouse at Agrocampus Ouest Center of Angers from 24 February $2014\left(\mathrm{~T}_{0}\right)$ to 30 June $2014\left(\mathrm{~T}_{\text {final }}\right)$. Four different growing media, with more or less similar particle size distributions $(5-15 \mathrm{~mm})$ were tested: a milled weakly decomposed Sphagnum peat coming from Latvia, a 50/50 vol. 6 month-composted/aged pine bark mix, coir (coco medium, produced in Ivory Coast), and wood fiber (obtained from fresh woodchip via a defibration process). Before potting, $\mathrm{pH}$ was adjusted to 6.0 with lime and a same $1.5 \mathrm{~kg} \mathrm{~m}^{-3}$ fertilisation 12 12-17 N-P-K was incorporated in each growing medium. 96 plastic pots (1.5 L, VCC15 TEKU, Pöppelmann, Rixheim, France) were filled with each growing medium previously wetted to a water potential equal to $-10 \mathrm{kPa}$ before planting cuttings of Rosa $\mathrm{x}$ hybrida "Radrazz" $\left(\mathrm{T}_{0}\right)$ into the growing media, whereas 54 were filled in the same way with each growing medium without plants (control). These 150 pots for each growing medium were spread over three different benches per growing medium (96 planted pots, called $\mathrm{P}$, and 54 not planted, NP) corresponding to three irrigation strategies, i.e. three different intensities of drying (corresponding to three thresholds in water potentials) before rewetting:

“-1" water potential always maintained at $-1 \mathrm{kPa}$, i.e. with an optimal water content;
"-10" irrigation triggered when water potential reached $-10 \mathrm{kPa}$, defined as the minimal water content of the easily available water;

"-30" irrigation triggered when water potential reached $-30 \mathrm{kPa}$, for which water stress conditions and then risks of peat hydrophobicity could occur.

In total, 600 pots (384 with plant, P, and 216 without plant, NP) were installed on 12 benches ( 3 for each growing medium), corresponding to 24 treatments (4 materials $\times 3$ irrigation regimes $\times 2 \mathrm{P} / \mathrm{NP}$ pots). Watering was managed by subirrigation with an ebb and flow system for “-10 kPa” and “-30 kPa” regimes, whereas the benches used for " $-1 \mathrm{kPa}$ " regime was covered beforehand with an Aquanap ${ }^{\circledR}$ irrigation sheet (Puteaux SA, Les Clayes sous Bois, France) bathing by its extremities in a gutter installed around each side of the bench so that the water level was adjusted to obtain a permanent water suction of $-0.1 \mathrm{~m}(-1 \mathrm{kPa})$ at the middle of the pot (more details in Cannavo et al., 2011). Water potential was controlled using three tensiometers (SKT850, SDEC, Reignac sur Indre, France) per bench (inserted in the planted pots) linked to a central acquisition (CR1000, Campbell Scientific, Antony, France). Watering was triggered when mean values of the three tensiometers raised the minimum water potential threshold and stopped at $-1 \mathrm{kPa}$. Irrigation water was fertilized with $2 \mathrm{~N}-3 \mathrm{P}-$ $6 \mathrm{~K}+0.6 \mathrm{MgO}\left(2.2 \mathrm{mmol} \mathrm{NO}_{3} \mathrm{~L}^{-1}, 1.8 \mathrm{mmol} \mathrm{PO}_{4} \mathrm{~L}^{-1}, 6.1 \mathrm{mmol} \mathrm{KL}^{-1}\right.$ and $0.9 \mathrm{mmol} \mathrm{Mg} \mathrm{L}^{-1}$ ).

\subsection{Root and physical parameters studied}

The parameters listed below were measured at the beginning, $\mathrm{T}_{0}$ (February 24, 2014), and the end, $\mathrm{T}_{\text {final }}$ (June 30, 2014), of the experiment.

Root and shoot biomass were measured on five pots per treatment with plants ( 4 growing medium $\times 3$ irrigation strategies). The roots were extracted from the growing media using tweezers under a water wash, and their volumes were measured according to the Archimede's principle by placing roots in a tea ball, which was immersed into a water recipient placed on a balance. Roots and aerial parts were then dried at $65^{\circ} \mathrm{C}$ for $24 \mathrm{~h}$ to determine their respective dry mass.

Wettability was estimated on four replicates per treatment (except for “- $1 \mathrm{kPa}$ " regime, see below) previously equilibrated to $-10 \mathrm{kPa}$ and $-30 \mathrm{kPa}$ water potentials from contact angle measurements by the capillary rise method described by Michel et al. (2001) using a Kruss Processor Tensiometer K12 ${ }^{\odot}$. According to these values of -10 and $-30 \mathrm{kPa}$ water potentials considered for the measurements, contact angles were not estimated for " $-1 \mathrm{kPa}$ " regime, which corresponds to an irrigation regime without risks of hydrophobicity due to the high water content maintained in the growing media during plant cultivation. Contact angles were determined from the equation of Washburn (1921) defining a liquid flow through a network of capillaries:

$\cos \theta=\frac{m^{2}}{t} \frac{\eta}{\rho^{2} \cdot \sigma \cdot c}$

where $t$ is the time (s), $m$ is the mass of adsorbed liquid (g), $\eta$ is the viscosity of the liquid (MPa), $\rho$ is the density of the liquid $\left(\mathrm{g} \mathrm{cm}^{3}\right), \sigma$ is the surface tension of the liquid $(\mathrm{mN} / \mathrm{m}), \theta$ is the contact angle between the sample and the liquid, and $c$ is a constant approximation of the porosity and tortuosity of the capillaries.

Water retention properties were determined on six pots per treatment using standardised hydrostatic methods (EN13041, 2000). After cutting the aerial part, in order to allow the needed contact between the growing media on the suction table, the base of each plastic pot was delicately cut and replaced by a Nylon cloth 
fixed to the pot, with the objective of causing minimum structure perturbation of the growing media. Pots were then saturated with water for $48 \mathrm{~h}$ and then placed on the suction table to equilibrate the growing media at $-1,-3.16,-5$ and $-10 \mathrm{kPa}$ successively. From this data, air-filled porosity (AFP) and easily available water (EAW) were calculated, knowing that:

$\mathrm{AFP}=\theta \mathrm{s}-\theta_{(-1 \mathrm{kPa})}$

$\mathrm{EAW}=\theta_{(-1 \mathrm{kPa})}-\theta_{(-10 \mathrm{kPa})}$

where $\theta \mathrm{s}, \theta_{(-1 \mathrm{kPa})}$, and $\theta_{(-10 \mathrm{kPa})}$ are the volumetric water contents at saturation, $-1 \mathrm{kPa}$ and $-10 \mathrm{kPa}$, respectively; and the water retention curves were modelled using the Van Genuchten (1980) model:

$\theta=\theta_{r}+\left(\theta_{s}-\theta_{r}\right) \times\left[\left(1+(\alpha \cdot \psi)^{n}\right)\right]^{-m}$

where $\psi$ is the water suction ( $\mathrm{kPa}), \theta$ is the volumetric water content $\left(\mathrm{m}^{3} \mathrm{~m}^{-3}\right), \theta_{s}$ is the saturation volumetric water content $\left(\mathrm{m}^{3} \mathrm{~m}^{-3}\right)$ corresponding to the total porosity presented above, $\theta_{r}$ is the residual volumetric water content $\left(\mathrm{m}^{3} \mathrm{~m}^{-3}\right)$ and $\alpha\left(\mathrm{kPa}^{-1}\right), n$ (dimensionless) and $m=1-1 / n$ (dimensionless) are fitting parameters.

Saturated hydraulic conductivity, $K_{\mathrm{S}}$, was directly estimated on four pots per treatment placed under constant water head (Klute and Dirksen, 1986) by the following equation:

$K_{\mathrm{s}}=\frac{V L}{[S t(\Delta \mathrm{H})]}$

where $V$ is the volume of water $\left(\mathrm{cm}^{3}\right)$ passing through the sample during the time $t(\mathrm{~s}), L$ is the length of the sample $(\mathrm{cm}), S$ is the section of the sample $\left(\mathrm{cm}^{2}\right)$, and $\Delta H$ is the height of the hydraulic gradient $(\mathrm{cm})$.

Unsaturated hydraulic conductivity is then described using the pore-size distribution model of Mualem (1976) combined with the Van Genuchten water retention model. Hydraulic conductivity was expressed as a function of the water suction:

$K(\psi)=K_{\mathrm{s}}\left(\frac{1-(\alpha \psi)^{n-2}\left[1+(\alpha \psi)^{n}\right]^{-m}}{\left[1+(\alpha \psi)^{n}\right]^{2 m}}\right)$

where $K_{\mathrm{s}}$ is the hydraulic conductivity at saturation and $\alpha, n$ and $m$ the fitting parameters coming from the Van Genuchten water retention model.

Pore tortuosity, $\tau_{\mathrm{w}}$, was calculated using the equation given by Caron and Nkongolo (2004):

$\tau_{\mathrm{w}}=\frac{0.00028 \rho g}{\eta K_{\mathrm{s}}} \int_{\theta_{\mathrm{r}}}^{\theta_{\mathrm{ea}}} \alpha^{2}\left(\Theta^{-1 / \mathrm{b}}-1\right)^{-2 / \mathrm{n}} \mathrm{d} \theta$

where $\eta$ is the viscosity of water (in Pas), $\rho$ is the density of the water $\left(\mathrm{g} \mathrm{cm}^{-3}\right), g$ is the gravity acceleration $\left(\mathrm{ms}^{-2}\right), K_{\mathrm{S}}$ is the saturated hydraulic conductivity $\left(\mathrm{ms}^{-1}\right), \theta_{\mathrm{ea}}$ is the water content at the air entry point $\left(\mathrm{m}^{3} \mathrm{~m}^{-3}\right), \theta_{\mathrm{r}}$ is the residual water content obtained $\left(\mathrm{m}^{3} \mathrm{~m}^{-3}\right)$ from the water retention model of Van Genuchten (1980), $\alpha, n$ and $m(=1-1 / n)$ are fitted parameters obtained from the Van Genuchten model, and $\Theta=\left(\theta-\theta_{\mathrm{r}}\right) /\left(\theta_{\mathrm{s}}-\theta_{\mathrm{r}}\right)$.

The pore tortuosity calculation was performed using Mathcad ${ }^{\circledR}$ software (PTC, Needham, MA, USA). Measurements of air entry point were directly performed on four replicates per treatment. After saturation, pots were placed on a suction table and the water level was lowered gradually by $1-\mathrm{cm}$ intervals as the changes in water contents were monitored by ECHO- 5 probes. The air entry point was defined as the spot where the first important drop in water content occurred as the water potential decreased. The determination procedure is detailed by Nemati et al. (2002).
Gas diffusivity $\left(D_{S} / D_{0}\right)$ was calculated according to the equation given by King and Smith (1987) as:

$\frac{D_{S}}{D_{0}}=\frac{\text { AFP }}{\tau_{\mathrm{w}}}$

where AFP is the air filled porosity, $D_{\mathrm{S}}$ is the gas diffusion coefficient within the media $\mathrm{cm}^{2} \mathrm{~s}^{-1}, D_{0}$ is the gas diffusion coefficient in air $\mathrm{cm}^{2} \mathrm{~s}^{-1}$, and $\tau_{\mathrm{w}}$ is the pore tortuosity of the growing media.

\subsection{Statistical treatment of data}

Considering each growing medium independently, statistical data processing was performed on all studied parameters (except for $\tau_{w}$, and $D_{S} / D_{0}$, resulting from calculations combining mean values of some other measured parameters), using the $\mathrm{R}$ software through ANOVA tests checking the following conditions beforehand: the independence of the values of the variables, the normality of the data distribution, using the Shapiro Wilk test (Moses et al., 1993), and the homogeneity of variance test of Bartlett (Tobias and Carlson, 1969). Mean differences were tested at the 95\% interval for $p$-values of $5 \%$ or for the first species error ( $R$ software).

\section{Results}

\subsection{Shoot and root growth (Table 1)}

At $\mathrm{T}_{\text {final }}$, shoot dry mass generally decreased in relation to the severity of the drying/wetting cycles for peat, coir, and wood fiber, except the "-10" and "-30" regimes for pine park which did not show any significant change. Statistical differences observed for the aerial part were even less important regarding the root volumes, which were however, relatively low compared to those obtained for similar Knock Out Rose by Cannavo and Michel (2013) on other peat growing media grown with a water regime maintained at $-1 \mathrm{kPa}$, but more or less equivalent to those obtained by Kerloch and Michel (2015) on similar growing media for which irrigation was triggered at $-10 \mathrm{kPa}$. Peat was the only growing medium showing decrease in root content for each value in the intensity of drying/wetting cycles. Root content was higher for "-1" for coir, and lower for " -30 " for wood fiber, in comparison to the other regimes. In the case of pine bark, any significant change in root content was observed, whatever the water regimes.

\subsection{General physical and hydraulic behaviours of planted pots $(P)$ vs time}

Whatever the intensity of the drying/wetting cycles, a small decrease in total volume close to $0.02-0.03 \mathrm{v} / \mathrm{v}$ was shown for all tested growing media from $T_{0}$ to $T_{\text {final }}$. This general decrease in total volume is, however, lower than those reported by Kerloch and Michel (2015), and mainly due to a high compaction when potting the growing media. The changes in water retention curves, and consequent AFP and EAW between $T_{0}$ to $T_{\text {final }}$ are also almost similar for fibrous materials (peat, coir and wood fiber), with an increase in water retention for $T_{\text {final }}$, especially in the lowest water suctions and for the lowest intensity of drying/wetting cycles ("-1"), whereas this evolution tends to decline and then becomes not statistically different for higher water suctions and higher intensity of drying/wetting cycles ("-30") in comparison with $\mathrm{T}_{0}$ (Fig. 1). A large decrease in AFP is also observed, varying according to the irrigation regimes between $0.08-0.14 \mathrm{v} / \mathrm{v}$ for peat, $0.10-0.15 \mathrm{v} / \mathrm{v}$ for wood fiber and $0.11-0.15 \mathrm{v} / \mathrm{v}$ for coir; and to a lower increase in EAW, varying between $0.02-0.04 \mathrm{v} / \mathrm{v}$ for peat, $0.04-0.06 \mathrm{v} / \mathrm{v}$ for wood fiber, and $0.08-0.10 \mathrm{v} / \mathrm{v}$ for coir (Table 1 ). The same tendency with a decrease in AFP (between 0.04-0.08 v/v) and an increase in EAW (between $0.03-0.05 \mathrm{v} / \mathrm{v}$ ) was also observed for pine bark. 
Table 1

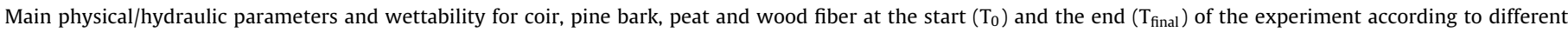

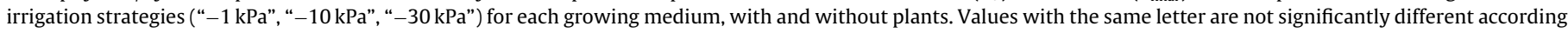
to $\operatorname{LSD}$ test $(\mathrm{P} \leq 0.05)$

\begin{tabular}{|c|c|c|c|c|c|c|c|}
\hline \multirow[t]{3}{*}{ Coir } & \multirow[t]{3}{*}{$\mathrm{T}_{0}$} & \multicolumn{6}{|l|}{$\mathrm{T}_{\text {final }}$} \\
\hline & & \multicolumn{3}{|c|}{ with plant } & \multicolumn{3}{|c|}{ without plant } \\
\hline & & -1 & -10 & -30 & -1 & -10 & -30 \\
\hline Shoot dry mass (g) & & $57.2 \mathrm{a}$ & $37.6 b$ & $17.5 \mathrm{c}$ & & & \\
\hline Root content $100 \times \mathrm{v} / \mathrm{v}$ & & $2.0 \mathrm{a}$ & $1.0 \mathrm{~b}$ & $1.1 \mathrm{~b}$ & & & \\
\hline Total porosity (v/v) & $0.952 \mathrm{a}$ & $0.935 b$ & $0.929 b$ & $0.928 b$ & $0.893 c$ & $0.886 c$ & $0.884 \mathrm{c}$ \\
\hline $\operatorname{AFP}(v / v)$ & $0.535 a$ & $0.386 \mathrm{~d}$ & $0.409 \mathrm{~cd}$ & $0.443 b$ & $0.407 \mathrm{~cd}$ & $0.427 \mathrm{bc}$ & $0.443 b$ \\
\hline EAW (v/v) & $0.103 a$ & $0.205 d$ & $0.184 c$ & $0.190 c$ & $0.178 c$ & $0.151 b$ & $0.145 b$ \\
\hline$\psi$ air entry $(-\mathrm{kPa})$ & $0.240 \mathrm{a}$ & $0.340 \mathrm{~b}$ & $0.520 c$ & $0.520 c$ & $0.280 \mathrm{ab}$ & $0.440 c$ & $0.480 c$ \\
\hline$\theta$ air entry $(\mathrm{v} / \mathrm{v})$ & $0.920 a$ & $0.920 \mathrm{a}$ & $0.910 \mathrm{a}$ & $0.920 \mathrm{a}$ & $0.875 b$ & $0.865 b$ & $0.865 b$ \\
\hline $\mathrm{K}_{\mathrm{S}}\left(\mathrm{cm} \mathrm{s}^{-1}\right)$ & $0.363 a$ & $0.492 b$ & $0.541 b$ & $0.630 c$ & $0.526 b$ & $0.583 \mathrm{bc}$ & $0.630 c$ \\
\hline Pore tortuosity, t & 16.3 & 6 & 3.9 & 3.5 & 7.1 & 4.3 & 3.8 \\
\hline $\mathrm{D}_{\mathrm{s}} / \mathrm{D}_{0}$ & 0.033 & 0.064 & 0.104 & 0.125 & 0.057 & 0.1 & 0.117 \\
\hline C. angle $\left(^{\circ}\right)$ at $-10 \mathrm{kPa}$ & $52.1 \mathrm{a}$ & & $56.4 \mathrm{~b}$ & & & $61.5 c$ & \\
\hline C. angle $\left(^{\circ}\right)$ at $-30 \mathrm{kPa}$ & $60.1 \mathrm{a}$ & & & $68.2 b$ & & & $73.0 \mathrm{c}$ \\
\hline \multirow[t]{3}{*}{ Peat } & $\mathrm{T}_{0}$ & \multicolumn{6}{|l|}{$\mathrm{T}_{\text {final }}$} \\
\hline & & \multicolumn{3}{|c|}{ with plant } & \multicolumn{3}{|c|}{ without plant } \\
\hline & & -1 & -10 & -30 & -1 & -10 & -30 \\
\hline Shoot dry mass (g) & & $42.9 a$ & $32.6 b$ & $25.5 c$ & & & \\
\hline Root content $100 \times \mathrm{v} / \mathrm{v}$ & & $2.7 \mathrm{a}$ & $2.1 \mathrm{~b}$ & $1.4 \mathrm{c}$ & & & \\
\hline Total porosity $(\mathrm{v} / \mathrm{v})$ & $0.944 a$ & $0.911 \mathrm{~b}$ & $0.910 \mathrm{~b}$ & $0.907 b$ & $0.902 b$ & $0.878 \mathrm{c}$ & $0.878 c$ \\
\hline $\operatorname{AFP}(v / v)$ & $0.463 a$ & $0.324 d$ & $0.340 \mathrm{~cd}$ & $0.381 b$ & $0.339 \mathrm{c}$ & $0.354 \mathrm{bc}$ & $0.369 b$ \\
\hline $\operatorname{EAW}(\mathrm{v} / \mathrm{v})$ & $0.144 \mathrm{a}$ & $0.189 c$ & $0.187 c$ & $0.167 b$ & $0.190 c$ & $0.167 b$ & $0.163 b$ \\
\hline$\psi$ air entry $(-\mathrm{kPa})$ & $0.10 \mathrm{a}$ & $0.680 c$ & $0.620 c$ & $0.640 c$ & $0.550 \mathrm{bc}$ & $0.460 \mathrm{~b}$ & $0.520 b c$ \\
\hline$\theta$ air entry $(\mathrm{v} / \mathrm{v})$ & $0.920 \mathrm{a}$ & $0.890 \mathrm{~b}$ & $0.880 \mathrm{~b}$ & $0.890 \mathrm{~b}$ & $0.890 \mathrm{~b}$ & $0.870 \mathrm{~b}$ & $0.840 \mathrm{c}$ \\
\hline $\mathrm{K}_{\mathrm{S}}\left(\mathrm{cm} \mathrm{s}^{-1}\right)$ & $0.117 \mathrm{~b}$ & $0.068 \mathrm{a}$ & $0.089 \mathrm{ab}$ & $0.259 c$ & $0.060 \mathrm{a}$ & $0.085 a b$ & $0.215 c$ \\
\hline Pore tortuosity, t & 142.9 & 21.2 & 18 & 6.6 & 28.7 & 23.7 & 8.3 \\
\hline $\mathrm{D}_{\mathrm{s}} / \mathrm{D}_{0}$ & 0.003 & 0.016 & 0.019 & 0.057 & 0.012 & 0.015 & 0.044 \\
\hline C. angle $\left(^{\circ}\right)$ at $-10 \mathrm{kPa}$ & $57.7 \mathrm{a}$ & & $62.5 b$ & & & $67.7 \mathrm{c}$ & \\
\hline C. angle $\left(^{\circ}\right)$ at $-30 \mathrm{kPa}$ & $67.4 a$ & & & $75,3 b$ & & & $79,4 \mathrm{c}$ \\
\hline \multirow[t]{3}{*}{ Pine bark } & $\mathrm{T}_{0}$ & \multicolumn{6}{|l|}{$\mathrm{T}_{\text {final }}$} \\
\hline & & \multicolumn{3}{|c|}{ with plant } & \multicolumn{3}{|c|}{ without plant } \\
\hline & & -1 & -10 & -30 & -1 & -10 & -30 \\
\hline Shoot dry mass (g) & & $20.2 \mathrm{a}$ & $11.3 \mathrm{~b}$ & $13.2 \mathrm{~b}$ & & & \\
\hline Root content $100 \times \mathrm{v} / \mathrm{v}$ & & $1.4 \mathrm{a}$ & $1.2 \mathrm{a}$ & $1.2 \mathrm{a}$ & & & \\
\hline Total porosity $(\mathrm{v} / \mathrm{v})$ & $0.855 a$ & $0.820 \mathrm{~b}$ & $0.822 b$ & $0.820 \mathrm{~b}$ & $0.818 \mathrm{~b}$ & $0.817 \mathrm{~b}$ & $0.819 b$ \\
\hline $\operatorname{AFP}(v / v)$ & $0.385 a$ & $0.305 c$ & $0.319 b c$ & $0.344 \mathrm{~b}$ & $0.315 b c$ & $0.335 b$ & $0.347 \mathrm{~b}$ \\
\hline EAW (v/v) & $0.080 \mathrm{a}$ & $0.121 \mathrm{~b}$ & $0.118 b$ & $0.132 b$ & $0.121 b$ & $0.114 b$ & $0.132 b$ \\
\hline$\psi$ air entry $(-\mathrm{kPa})$ & $0.120 \mathrm{a}$ & $0.400 \mathrm{c}$ & $0.560 \mathrm{~d}$ & $0.700 \mathrm{e}$ & $0.300 \mathrm{~b}$ & $0.450 c$ & $0.700 \mathrm{e}$ \\
\hline$\theta$ air entry $(\mathrm{v} / \mathrm{v})$ & $0.840 \mathrm{a}$ & $0.790 \mathrm{~b}$ & $0.770 \mathrm{bc}$ & $0.770 \mathrm{bc}$ & $0.790 \mathrm{~b}$ & $0.760 c$ & $0.760 c$ \\
\hline $\mathrm{K}_{\mathrm{S}}\left(\mathrm{cm} \mathrm{s}^{-1}\right)$ & $0.221 \mathrm{a}$ & $0.188 a$ & $0.387 b$ & $0.383 b$ & $0.194 a$ & $0.327 \mathrm{~b}$ & $0.322 \mathrm{~b}$ \\
\hline Pore tortuosity,t & 40.2 & 10.1 & 3.9 & 3.6 & 14 & 5.8 & 4.3 \\
\hline $\mathrm{D}_{\mathrm{s}} / \mathrm{D}_{0}$ & 0.01 & 0.029 & 0.082 & 0.095 & 0.023 & 0.058 & 0.081 \\
\hline C. angle $\left(^{\circ}\right)$ at $-10 \mathrm{kPa}$ & $61.5 a$ & & $65.2 b$ & & & $70.8 \mathrm{c}$ & \\
\hline C. angle $\left({ }^{\circ}\right)$ at $-30 \mathrm{kPa}$ & $69.4 a$ & & & $77.2 \mathrm{~b}$ & & & $82.2 \mathrm{c}$ \\
\hline \multirow[t]{3}{*}{ Wood fiber } & $\mathrm{T}_{0}$ & \multicolumn{6}{|l|}{$\mathrm{T}_{\text {final }}$} \\
\hline & & with pla & & & without & & \\
\hline & & -1 & -10 & -30 & -1 & -10 & -30 \\
\hline Shoot dry mass (g) & & $13.3 a$ & $3.3 \mathrm{~b}$ & $0.9 \mathrm{c}$ & & & \\
\hline Root content $100 \times \mathrm{v} / \mathrm{v}$ & & $1.4 \mathrm{a}$ & $1.3 \mathrm{a}$ & $0.6 b$ & & & \\
\hline Total porosity (v/v) & $0.963 a$ & $0.943 b$ & $0.939 b$ & $0.937 b$ & $0.924 c$ & $0.923 c$ & $0.921 c$ \\
\hline $\operatorname{AFP}(v / v)$ & $0.657 \mathrm{a}$ & $0.526 c$ & $0.539 \mathrm{bc}$ & $0.556 b$ & $0.524 c$ & $0.548 \mathrm{bc}$ & $0.557 b$ \\
\hline EAW (v/v) & $0.111 \mathrm{a}$ & $0.149 b$ & $0.147 b$ & $0.167 c$ & $0.190 d$ & $0.175 \mathrm{~cd}$ & $0.188 d$ \\
\hline$\psi$ air entry $(-\mathrm{kPa})$ & $0.240 \mathrm{a}$ & $0.400 \mathrm{~b}$ & $0.450 \mathrm{bc}$ & $0.500 \mathrm{c}$ & $0.450 \mathrm{bc}$ & $0.500 \mathrm{c}$ & $0.520 c$ \\
\hline$\theta$ air entry $(\mathrm{v} / \mathrm{v})$ & $0.940 \mathrm{a}$ & $0.940 a$ & $0.925 \mathrm{ab}$ & $0.900 \mathrm{~b}$ & $0.915 a b$ & $0.885 \mathrm{bc}$ & $0.875 c$ \\
\hline $\mathrm{K}_{\mathrm{S}}\left(\mathrm{cm} \mathrm{s}^{-1}\right)$ & $0.989 a$ & $1.659 b$ & $1.744 \mathrm{~b}$ & $1.778 \mathrm{~b}$ & $1.188 \mathrm{a}$ & $1.188 \mathrm{a}$ & $1.098 \mathrm{a}$ \\
\hline Pore tortuosity, t & 6.8 & 1.7 & 1.7 & 1.7 & 2.4 & 2.5 & 2.6 \\
\hline $\mathrm{D}_{\mathrm{s}} / \mathrm{D}_{0}$ & 0.096 & 0.304 & 0.316 & 0.335 & 0.218 & 0.224 & 0.212 \\
\hline C. angle $\left(^{\circ}\right)$ at $-10 \mathrm{kPa}$ & $67.0 \mathrm{a}$ & & $70.2 b$ & & & $74.1 \mathrm{c}$ & \\
\hline C. angle $\left(^{\circ}\right)$ at $-30 \mathrm{kPa}$ & 71.9a & & & $77.4 \mathrm{~b}$ & & & $80.2 c$ \\
\hline
\end{tabular}



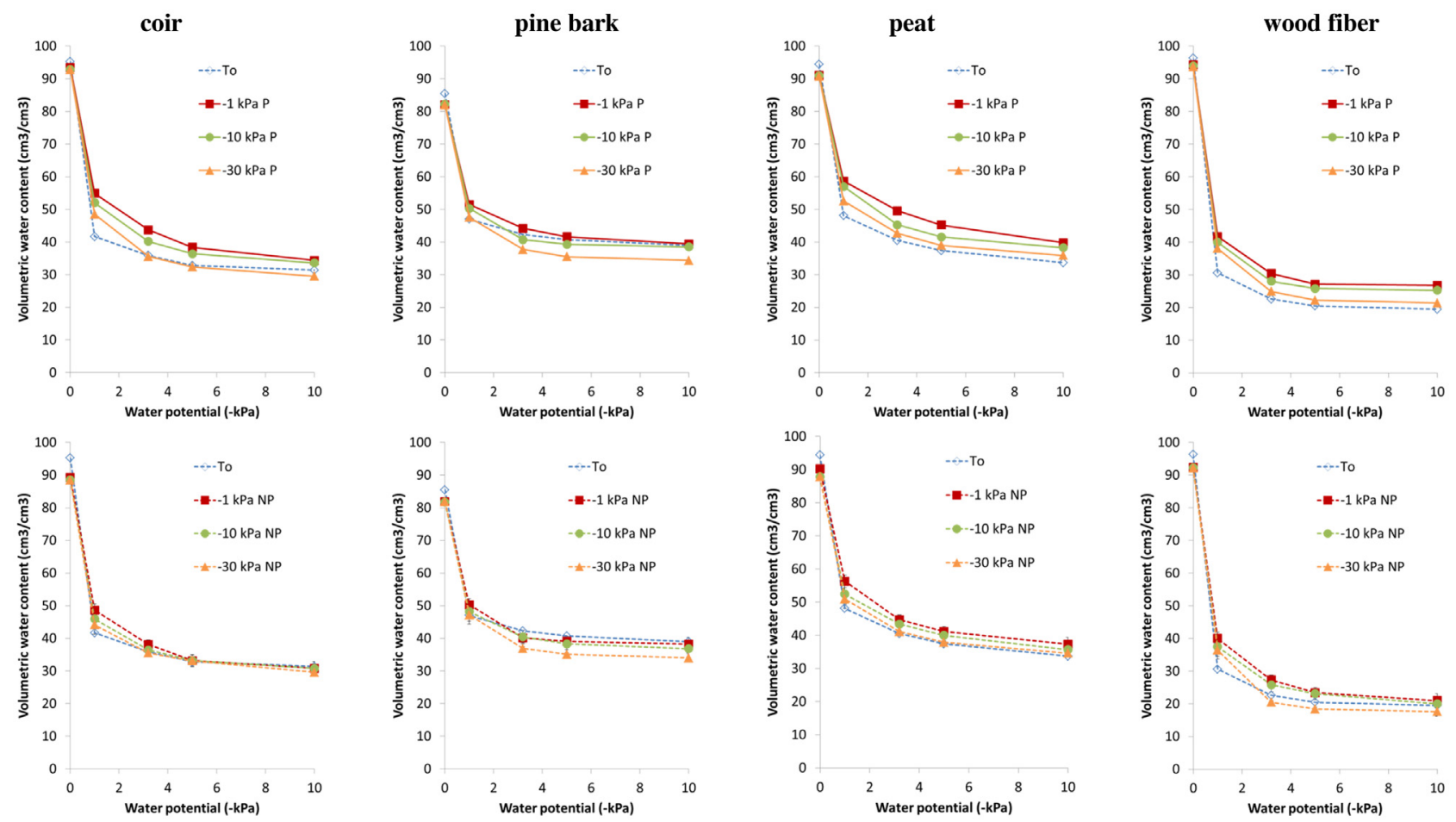

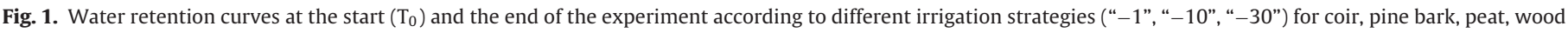
fiber, with (P) and without plants (NP). Standard deviation for each measured value did not exceed $2 \%$.

But the evolution in water retention between $T_{0}$ to $T_{\text {final }}$ is a little bit different for pine bark depending on irrigation regimes. For the lowest intensity of drying/wetting cycles ("-1" and "-10"), a low increase in water retention was only shown at $-1 \mathrm{kPa}$ water suction, but no significant change was observed at higher suctions, whereas no difference at $-1 \mathrm{kPa}$ water suction and a small degradation in water retention were observed for other suctions in the case of "-30" irrigation regime (Fig. 1). Although there was a high compaction of the growing media tested, hence reducing the irreversible loss in volume observed by Qi et al. (2011) during the first drying/wetting cycles and also limiting the degradation in AFP, these results are in agreement with those obtained by Allaire-Leung et al. (1999), Nkongolo and Caron (2006), Cannavo et al. (2011), Cannavo and Michel (2013) on peat based growing media, and also those reported by Kerloch and Michel (2015) on the same types of materials.

At the beginning, as well as at the end of the experiment, growing media were partially hydrophilic and can be classified in the ascending order of their wettability: wood fiber < pine bark < peat $<$ coir, with the range of values quite close to those collected by Michel (2015). But contact angles increased from $T_{0}$ to $T_{\text {final }}$ the more the intensity of drying before watering was high, with $+3.2^{\circ}$, $+3.7^{\circ},+4.3^{\circ},+4.8^{\circ}$ for the " $-10 \mathrm{kPa}$ " regime and $+5.5^{\circ},+7.8^{\circ},+8.1^{\circ}$, $+7.9^{\circ}$ for the " $-30 \mathrm{kPa}$ " regime, considering wood fiber, pine bark, coir and peat, respectively (Table 1 ).

Evolutions in saturated hydraulic conductivity, $K_{S}$, between $T_{0}$ to $\mathrm{T}_{\text {final }}$ were relatively small, and sometimes opposite according to the irrigation regimes. In comparison with $\mathrm{T}_{0}$, values obtained for the higher intensity of drying/wetting cycles ("-30") were approximately 2 times higher, whereas smaller increases and sometimes opposite results (small decreases in $\mathrm{K}_{\mathrm{S}}$ for peat and pine bark at " -1 " and for peat at "-10" regimes) were shown for the other irrigation regimes (Table 1 ). In opposition to $K_{S}, K(\Psi)$ curves obtained using the Van Genuchten model showed large differences, with increases varying between 1.5-3 orders of magnitude from $T_{0}$ to $\mathrm{T}_{\text {final (Fig. 2). }}$
A large decrease in pore tortuosity for all growing media tested was shown at the end of the experiment, as already mentioned in previous references. Values obtained for $\mathrm{T}_{0}$ and $\mathrm{T}_{\text {final }}$ are also in the same order with wood fiber $<$ coir $<$ pine bark $<$ peat, with lower differences at the end of the experiment in comparison to $\mathrm{T}_{0}$. This decrease in pore tortuosity is even more important with the intensity of drying/wetting cycles for peat, pine bark and coir, whereas no change was obtained at the end of the experiment for wood fiber, showing very low values in pore tortuosity whatever the irrigation regime (Table 1 ).

Regarding $\mathrm{D}_{\mathrm{S}} / \mathrm{D}_{0}$ at $\mathrm{T}_{0}$, pine bark (0.010), and moreover peat (0.03), exhibited lower values than the 0.015 minimum threshold reported by Caron et al. (2010), in comparison with coir (0.033) and wood fiber (0.096). However, the same evolution was shown over time with large increases in $D_{S} / D_{0}$ and as a function of the intensity of drying/wetting cycles (Table 1 ).

\subsection{Effects of root development}

Comparing pots with (P) or without (NP) plants for the same irrigation regime showed that the important changes in physical and hydraulic properties over time led to close values with or without plants at the end of the experiment. However, some differences have to be mentioned.

Total porosity is higher for peat, wood fiber, coir, or equivalent for pine bark for pots with plants $(\mathrm{P})$ compared to those without plants (NP), although the root volume occupying its porosity, indicating the ability to the root system to limit the consolidation of growing media reported by Qi et al. (2011) on other organic growing media without plants submitted to several drying/wetting cycles (Table 1). Also, a general increase in water retention was underlined for planted pots, confirming conclusions already mentioned by Allaire-Leung et al. (1999), Nkongolo and Caron (2006), Cannavo and Michel (2013) and Kerloch and Michel (2015), with a general reduction in pore size due to the root development mainly in the coarser porosity (macroporosity) (Fig. 1). However, the combina- 

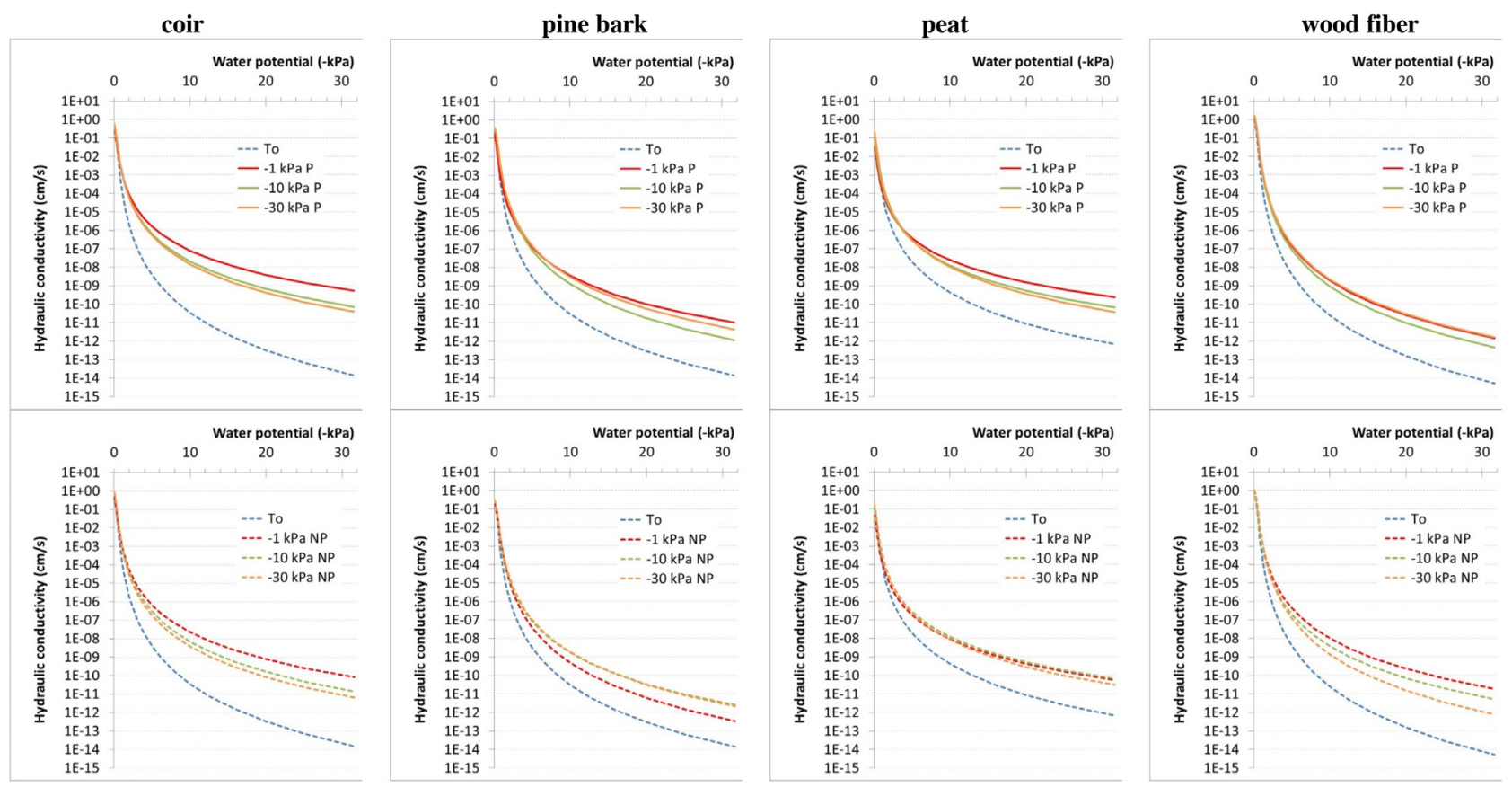

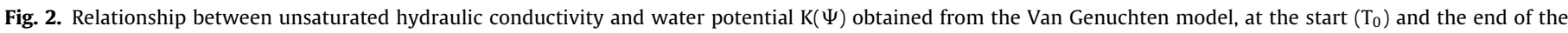
experiment according to different irrigation strategies (“-1", “-10”, “-30”) for coir, pine bark, peat, wood fiber, with (P) and without plants (NP).

tion of both higher total volume and water retention for pots with plants $(\mathrm{P})$ compared to those without plants (NP) did not lead to significant changes in AFP and EAW (Table 1).

Any general tendency in $K_{S}$ (Table 1 ) and $K(\Psi)$ (Fig. 2) changes was reported between the growing media tested, for which the differences between planted (P) and not planted (NP) pots were relatively small. In opposition to that, a lower pore tortuosity and higher relative gas diffusivity with the presence of roots were highlighted for all growing media (Table 1). This result supported interpretations given by Allaire-Leung et al. (1999) and Nkongolo and Caron (2006), and Kerloch and Michel (2015) on the positive impact of roots on pore connectivity and hence oxygen flows.

Furthermore, an important change was shown for contact angles which were lower for planted pots, hence suggesting a significant effect of the root system for improving the wettability of growing media (Table 1 ).

\subsection{Effect of intensity of drying/wetting cycles}

Results referring shoot dry mass and root content were already described above, showing more or less decreases with the intensity of drying/wetting cycles.

Whatever the presence (P) or not (NP) of roots, important changes in air and water contents and flows were shown as a function of irrigation regimes for peat, coir and pine bark. In detail, the greater the intensity of drying, the greater the AFP (from +0.04 and +0.06 between " -1 " and " -30 ") and pore connectivity (i.e. pore tortuosity 2-3 times lower from " -1 " to " -30 "), and hence, the relative gas diffusivity increased (2.5-4 times higher from " -1 " to " -30 ") (Table 1). In contrast, water retention decreased in the range of -1 to $-10 \mathrm{kPa}$ water potentials studied from " -1 " to “-30" irrigation regimes (Fig. 1), without any effect on EAW (Table 1) and on $K(\Psi)$ (Fig. 2). A decrease in wettability was also observed, increasing with the intensity of the drying/wetting cycles, as already shown in our previous results (Michel et al., 2001; Kerloch and Michel, 2015) (Table 1). In the case of the wood fiber, a same evolution as the other materials was observed in relation to the severity of the irrigation regimes (from " -1 " to "-30") with (1) an increase in AFP,
(2) a decrease in water retention, (3) without changes in EAW and $K(\Psi)$, as well as (4) the decrease in wettability which was however, lower than those observed for the other growing media. But, unlike the other growing media, no change in pore tortuosity and relative gas diffusivity with the effect of intensity of drying/wetting cycles was reported for wood fiber which is the coarser material, exhibiting substantially higher values in AFP and moreover in pore connectivity, $K_{S}$ and $D_{S} / D_{0}$ than the other growing media (Table 1 ).

\section{Discussion}

Analysing these results seemed to confirm the decrease in wettability as one of the most relevant parameters explaining the evolutions of physical and hydraulic properties of growing media according to irrigation regimes and to root development.

\subsection{Wettability vs irrigation regimes}

Maintaining irrigation regime in high water contents as for the “- 1 " regime did not lead to a degradation in growing media's wettability, so that the changes in air and water contents and flows at $\mathrm{T}_{\text {final }}$ compared to $\mathrm{T}_{0}$ were in agreement with observations already given by most of references previously mentioned (Allaire-Leung et al., 1999; Cannavo and Michel, 2013; Kerloch and Michel, 2015), and completed with (1) a decrease in total volume associated with an increase in water retention properties, leading to (2) large decreases in AFP but also (3) decreases in pore tortuosity, leading to (4) increases in $D_{S} / D_{0}$ and $K(\Psi)$. In contrast, when the intensity of drying/wetting cycles was higher, decreases in wettability were observed, with increases in contact angles varying between +3.2 to +4.8 for " -10 " regime and between +5.5 to +8.1 for " -30 " regime. As a consequence, the increase in water retention, shown in our trials and mentioned in previous references for growing media managed in high water contents, gradually disappeared for "-10" and more for "-30". These observations rejoined relationships between wettability and water contents emphasized by Michel et al. (2001), Fields et al. (2014), Michel (2015) on some growing media, and moreover the degradation in physical properties of growing media 
as the result of their degradation in wettability for growing media without plants, reported by Naasz et al. (2008) and Qi (2011) during drying/wetting cycles. By using the Van Genuchten's water retention model with different pore domains in which they integrated the contact angles, they explained the degradation in water retention properties by the drainage of the coarser porosity $(<-20 \mathrm{kPa})$ during the drying processes which became more hydrophobic, whereas the finest porosity $(>-20 \mathrm{kPa}$ ) remained filled by water and then hydrophilic. This interpretation could be considered in our experiments for explaining the degradation in water retention according to the intensity of drying/wetting cycles, and as a consequence, the increases in AFP from " -1 " to " -30 " irrigation regimes. Generating preferential paths is often reported as a common consequence of the degradation in wettability (Ritsema et al., 1993; Dekker and Ritsema, 1994, 2000; Ritsema and Dekker, 1994, 2000; Bauters et al., 2000; Dekker et al., 2000; etc.). On the basis of the interpretations given by Naasz et al. (2008) and Qi (2011), increases in AFP and even more so the preferential paths, generated by the decrease in wettability of the coarser porosity, probably facilitated connection of this coarser porosity filled with air, and hence led to increases in relative gas diffusivity and also in $\mathrm{K}_{\mathrm{S}}$, observed with the intensity of drying/wetting cycles for coir, pine bark and peat. In contrast, the finest porosity remained filled with water and hydrophilic, explaining that no significant changes in $\mathrm{K}(\Psi)$ were observed between irrigation regimes. For wood fiber, the smaller degradation in wettability and substantially higher AFP, pore connectivity, $K_{S}$ and $D_{S} / D_{0}$, in comparison with the other growing media and already observed for " -1 " regime, probably prevented the same evolutions for these parameters, which remained constant whatever the intensity of drying/wetting cycles.

\subsection{Wettability vs root development}

Although small differences were shown between pots with (P) or without (NP) plants, probably due to the low root contents, higher water retentions were reported for planted pots in comparison with those without plants, mostly for the " -1 " regime. This observation was in agreement with interpretations mentioned by some authors (Allaire-Leung et al., 1999; Nkongolo and Caron, 2006; Caron et al., 2010; Cannavo and Michel, 2013; Kerloch and Michel, 2015), explaining that roots generated the slightly finest and more connected porosity, and then higher air flows. This also supported relationships described below between both increases in water contents and in wettability for "-10" and "-30" irrigation regimes (i.e. a decrease in contact angles) for pots with plants, $P$, compared to those without plants, NP, despite very low root contents. The increases in the ratio microporosity $v s$ macroporosity due to the roots could also be proposed for explaining those in wettability, considering that, as suggested by Naasz et al. (2008), Qi (2011) and Michel et al. (2013), microporosity was filled with water and remained hydrophilic, while macroporosity was filled with air and became hydrophobic.

\section{Conclusion}

The respective amplitudes in changes according to both irrigation regimes and root development seemed to suggest that the hydric history (and the intensity of drying/wetting cycles) played a main role in the evolution of physical/hydraulic properties of the growing media.

The hydric history generated a decrease in total volume due to physical consolidation of growing media and the reduction of pore size distribution, improving water retention properties, pore connectivity and water and air flows for $\mathrm{T}_{\text {final }}$ in comparison to $\mathrm{T}_{0}$. However, increasing the severity of drying/wetting cycles pro- gressively reduce then cancel the improvement in water retention properties previously mentioned due to a decrease in wettability of the growing media. Moreover, the hypothesis of a variation in wettability as a function of pore size domains, with a coarser porosity becoming more hydrophobic and associated with preferential paths, and a finer porosity remaining filled with water and hydrophilic, could explain higher AFP, relative gas diffusive and $\mathrm{K}_{\mathrm{S}}$, in one hand, and the absence in significant $K(\Psi)$ variations in the other hand, observed for coir, pine bark and peat, whereas substantial higher values in AFP, pore connectivity, $D_{S} / D_{0}, K_{S}$, and a smaller degradation in wettability for wood fiber, seemed to prevent similar evolutions. Considering the evolutions of the whole of these parameters suggested that the degradation in wettability, and the resulting degradation in water retention properties, was one of the main constraints explaining lower shoot dry mass and root contents as a function of intensity of irrigation regimes.

This study confirmed conclusions previously reported in the literature, with a reduction in pore size and tortuosity due to root growth, and hence increases in water retention properties and relative gas diffusivity. Results also indicated that roots limited physical consolidation (loss in total porosity) of the growing media, and even more, limited the degradation in wettability. However, this work also underlined that the effects of root development s.s. were in lower amplitude than those due to the hydric history.

In the context of this study, based on the use of various organic growing media all presenting initial high aeration properties compared to limiting water retention properties (as defined by de Boodt and Verdonck, 1972), the whole of these results confirmed one more time the crucial importance of wettability in terms of evolution of physical/hydraulic properties of growing media and consequences on root and plant growth.

\section{Acknowledgements}

This study was carried out within the EPHor research unit at Agrocampus Ouest, Centre of Angers. The authors would like to thank the companies' partners (Agrauxine, Aquiland, Biolandes Pin Decor, Dumona, Premier Tech Falienor, Fertil, Florentaise, Floragard, If Tech, Klasmann-Deilmann, Peltracom) and French Administration (Agrocampus Ouest, Angers Loire Metropole) for funding support of the "Ecol'eau Terreau" project; the INEM Team of Agrocampus Ouest for experimental and technical overseeing in greenhouses; and Yvette Barraud-Roussel, Claudie Mazzega, Dominique Lemesle and Gérard Sintès for technical support in laboratory measurements.

\section{References}

Allaire-Leung, S.E., Caron, J., Parent, L.E., 1999. Changes in physical properties of peat substrates during plants growth. Can. J. Soil Sci. 79, 137-139.

Bauters, T.W.J., Steenhuis, T.S., Di Carlo, D.A., Nieber, J.L., Dekker, L.W., Ritsema, C.J., Parlange, J.Y., Haverkamp, R., 2000. Physics of water repellent soils. J. Hydrol. 231-232, 233-243.

Cannavo, P., Michel, J.C., 2013. Peat particle size effects on spatial root distribution, and changes on hydraulic and aeration properties. Sci. Hort. 151, 11-21.

Cannavo, P., Hafdhi, H., Michel, J.C., 2011. Impact of root growth on the physical properties of peat substrate under a constant water regimen. Hortsci 46, 1394-1399

Caron, J., Nkongolo, V.K.N., 2004. Assessing gas diffusion coefficients in growing media from in situ water flow and storage measurements. Vadose Zone J. 3, 300-311.

Caron, J., Morel, P., Rivière, L.M., Guillemain, G., 2010. Identifying appropriate methodology to diagnose aeration limitations with large peat and bark particles in growing media. Can. J. Soil Sci. 90, 481-494.

da Silva, F.F., Wallach, R., Chen, Y., 1993. Hydraulic properties of sphagnum peat moss and tuff (scoria) and their potential effects on water availability. Plant Soil 154, 119-126.

de Boodt, F., Verdonck, O., 1972. The physical properties of the substrates in horticulture. Acta Hort. 26, 37-44

Dekker, L.W., Ritsema, C.J., 1994. How water moves in a water repellent sandy soil 1: Potential and actual water repellency. Water Resour. Res. 30, 2507-2517. 
Dekker, L.W., Ritsema, C.J., 2000. Wetting patterns and moisture variability in water repellent Dutch soils. J. Hydrol. 231-232, 148-164.

Dekker, L.W., Ritsema, C.J., Oostindie, K., 2000. Wettability and wetting rate of Sphagnum peat and turf on dune sand affected by surfactant treatments. In Rochefort, L., Daigle, J.-Y. (Eds.), Proc. 11th Int. Peat Cong., Vol. 2. Edmonton, Alberta, Canada, pp. 566-574.

EN 13041, 2000. Amendements du sol et supports de culture-Détermination des propriétés physiques-Masse volumique apparente sèche, volume d'air, volume d'eau, valeur de rétraction et porosité totale (Association Française de Normalisation, Paris, France).

Fields, J.S., Fonteno, W.C., Jackson, B.E., 2014. Hydration efficiency of traditional and alternative greenhouse substrate components. Hortsci 49, 336-342.

Fonteno, W.C., Cassel, D.K., Larson, R.A., 1981. Physical properties of three container media and their effect on Poinsettia growth. J. Amer. Soc. Hort. Sci. 106, 736-741.

Gruda, N., Schnitzler, W.H., 2004. Suitability of wood fiber substrates for production of vegetable transplants II: The effect of wood fiber substrates and their volume weights on the growth of tomato transplants. Sci. Hort. 100, 333-340.

Heiskanen, J., 1995. Physical properties of two-component growth media based on sphagnum peat and their implications for plant-available water and aeration. Plant Soil 172, 45-54.

Kerloch, E., Michel, J.C., 2015. Pore tortuosity and wettability as main characteristics of the evolution of hydraulic properties of organic growing media during cultivation. Vadose Zone J. 14 (6), http://dx.doi.org/10.2136/ vzj2014.11.0162.

King, J.A., Smith, K.A., 1987. Gaseous diffusion through peat. J. Soil Sci. 38, 173-177.

Klute, A., Dirksen, C., 1986. Hydraulic conductivity and diffusivity: laboratory methods. In: Klute, A. (Ed.), Methods of Soil Analysis, Part 1. Physical and Mineralogical Methods. Amer. Soc. Agro., Madison, pp. 687-734.

Michel, J.C., Rivière, L.M., Bellon-Fontaine, M.N., 2001. Measurement of the wettability of organic materials in relation to water content by the capillary rise method. Eur. J. Soil Sci. 52, 459-467.

Michel, J.C., 2015. Wettability of organic growing media used in Horticulture: a review. Vadose Zone J. 14 (6), http://dx.doi.org/10.2136/vzj2014.09.0124.
Michel, J.C., Qi, G., Charpentier, S., 2013. Water repellency of peats: a main factor influencing the evolution of their physical properties. Acta Hort. 1013, 167-174.

Moses, L.E., Shapiro, D., Littenberg, B., 1993. Combining independent studies of a diagnostic test into a summary roc curve: data-analytic approaches and some additional considerations. Stat. Med. 12 (14), 1293-1316.

Mualem, Y., 1976. A new model for predicting the hydraulic conductivity of unsaturated porous media. Water Resour. Res. 12, 513-522.

Naasz, R., Michel, J.C., Charpentier, S., 2005. Measuring hydraulic properties of peat and pine bark using a transient method. Soil Sci. Soc. Am. J. 69, 13-22.

Naasz, R., Michel, J.C., Charpentier, S., 2008. Water repellency of organic growing media and its influence on hysteretic water retention properties. Eur. J. Soil Sci. 59, 156-165.

Nemati, R., Caron, J., Banton, O., Tardif, P., 2002. Determining air entry in peat substrates. Soil Sci. Soc. Am. J. 66, 367-373.

Nkongolo, N.V., Caron, J., 2006. Pore space organization and plant response in peat substrates: II. Dendrathemum morifolium Ramat. Sci. Res. Essay 1, 93-102.

Qi, G., Michel, J.C., Boivin, P., Charpentier, S., 2011. A laboratory device for continual measurement of water retention and shrink/swell properties during drying/wetting cycles. Hortsci 46, 1298-1302.

Qi, G., 2011. Hydrophobie des matières organiques utilisées comme substrat et conséquences sur l'hystérèse et l'évolution de leurs propriétés hydrodynamiques. In: Ph.D. Agrocampus Ouest, Angers, France

Ritsema, C.J., Dekker, L.W., 1994. How water moves in a water-repellent sandy soil. 2. Dynamics of fingered flow. Water Resour. Res. 30, 2519-2531.

Ritsema, C.J., Dekker, L.W., 2000. Preferential flow in water repellent sandy soils: principles and modeling implications. J. Hydrol. 231-232, 308-319.

Ritsema, C.J., Dekker, L.W., Hendrickx, J.M.H., Hamminga, W., 1993. Preferential flow mechanism in a water-repellent sandy soil. Water Resour. Res. 29, 2183-2193.

Tobias, S., Carlson, J.E., 1969. Brief report: bartlett's test of sphericity and chance findings in factor analysis. Multivar. Behav. Res. 4 (3), 375-377.

Van Genuchten, M.T., 1980. A closed-form equation for predicting hydraulic conductivity of unsaturated soils. Soil Sci. Soc. Am. J. 44, 892-898.

Wallach, R., da Silva, F.F., Chen, Y., 1992. Unsaturated hydraulic characteristics of composted agricultural wastes, tuff and their mixtures. Soil Sci. 153, 434-441.

Washburn, E.W., 1921. The dynamics of capillary flow. Phys. Rev. 17, 273-283. 